Dev Neurosci 2013;35:88-101

DOI: $10.1159 / 000346155$
Received: August 3,2012

Accepted after revision: October 15, 2012

Published online: February 22, 2013

\title{
Caspases Playing in the Field of Neuroinflammation: Old and New Players
}

\author{
Jose L. Venero ${ }^{\mathrm{a}}$ Miguel A. Burguillos ${ }^{\mathrm{b}}$ Bertrand Joseph ${ }^{\mathrm{b}}$ \\ ${ }^{a}$ Departamento de Bioquímica y Biología Molecular, Facultad de Farmacia, Universidad de Sevilla, and Instituto \\ de Biomedicina de Sevilla (IBiS), Sevilla, Spain; ${ }^{b}$ Department of Oncology-Pathology, Cancer Centrum Karolinska, \\ Karolinska Institutet, Stockholm, Sweden
}

\section{Key Words}

Caspase- 1 - Caspase-3 $\cdot$ Caspase- $8 \cdot$ Inflammation •

Apoptosis $\cdot$ Cytokines $\cdot$ Microglia $\cdot$ Inflammasome

\begin{abstract}
Neuroinflammation is a complex immune response against the harmful effects of diverse stimuli within the central nervous system. Caspases are a family of intracellular cysteine proteases that mediate proteolytic events indispensable for transduction of signaling pathway-controlling biological phenomena such as apoptosis and inflammation. To date, 14 players have been identified in mammals. For many years, caspases were simply divided into 'apoptotic' and 'proinflammatory' caspases and this classification remains useful to some extent. However, increasing evidence indicates that many of these so-called apoptotic caspases also exert nonapoptotic functions. In addition, the role of certain members of the supposed inflammatory caspases in the inflammatory process per se has also been discussed. In this review, we highlight the role for 'apoptotic' and 'proinflammatory' caspases in the regulation of the inflammation response with a special focus on the central nervous system.
\end{abstract}

Copyright $\odot 2013$ S. Karger AG, Basel
(C) 2013 S. Karger AG Basel

0378-5866/13/0353-0088\$38.00/0

\section{Caspases: Players Wearing Different Numbers}

Caspases are a family of intracellular cysteine proteases that recognize certain tetrapeptide motifs and cleave after an aspartate residue in their substrates. Once activated by a specific stimulus, caspases execute limited proteolysis of downstream substrates to trigger a cascade of events that culminates in the desired biological response. Caspases are recognized as key mediators of several biological processes including apoptosis (programmed cell death), necrosis, proliferation, differentiation and inflammation.

The history of caspases began more than 2 decades ago with the identification of an aspartate-specific protease activity involved in the conversion of the $31-\mathrm{kDa}$ prointerleukin- $1 \beta$ precursor to its $17-\mathrm{kDa}$ biologically active form $[1,2]$, and the subsequent identification of interleukin-1 $\beta$-converting enzyme as the protease responsible for this maturation $[3,4]$. Interleukin- $1 \beta$ converting enzyme was later on referred to as caspase-1 being the first identified member of the family of proteases currently known as caspases. Caspase- 1 is also the founding member of a subclass of caspases termed inflammatory caspases involved in cytokine maturation and the inflammatory responses.

\section{KARGER}

E-Mail karger@karger.com

www.karger.com/dne
Bertrand Joseph

Department of Oncology-Pathology

Cancer Centrum Karolinska, Karolinska Institutet

SE-171 77 Stockholm (Sweden)

E-Mail bertrand.joseph@ki.se 
In 1993, the discovery of the Caenorhabditis elegans cell death gene ced-3, which shares homologies with caspase- 1 and is involved in programmed cell death taking place during the development of this nematode, indicated that caspases might play fundamental roles in apoptosis [5]. Further demonstration that the overexpression of caspase- 1 is able to induce apoptosis in mammalian cells [6] and finally the characterization of caspase-3, as a critical mediator of the endogenous apoptotic pathway in mammalian cells $[7,8]$, literally propulsed the caspases into the field of apoptosis $[9,10]$. Worth a notice, although the first indications that caspases are important mediators of inflammatory responses, the vast majority of research has been pursued on their function during apoptosis. As an illustration, to date (by July 2012) the words 'caspase AND inflammation' used as search terms recover 3,374 hits in Pubmed, as compared to the 44,403 hits if 'caspase AND cell death' are used as key words.

To date, 14 mammalian caspases have been identified. They all have been attributed a number assigned based on their date of publication [11]. The human genome was found to encode 11 or 12 caspases (caspase-1 to caspase-10 and caspase-14 and caspase-12 depending on certain hereditary polymorphisms), whereas 10 caspases were found to be encoded by the mouse genome (caspases- $1,-2,-3,-6,-7,-8,-9,-11,-12$ and -14). Sequence analysis suggests that both human caspase- 4 and caspase- 5 most probably arose following the duplication of a caspase-11 ancestor gene [12]. The human caspase-12 gene is subject to polymorphism, which can generate a fulllength caspase protein or a truncated form. The fulllength form appears to be confined to people of African descent [13]. Human caspase-10 has no known orthologue in mice $[14,15]$. Caspase-13 turned out to be a bovine homolog of human caspase-4 [16].

Caspase family members share a number of distinct features. In fact, the name 'caspase' is a contraction of cysteine-dependent aspartate-specific protease and was chosen to reflect their enzymatic properties. Caspases are governed by a dominant specificity for protein substrates containing aspartate and by the use of a cysteine side chain for catalyzing peptide bond cleavage $[11,17]$. The use of the sulfur atom in the cysteine residue to cleave polypeptide chains is common to several protease families. However, the strong preference of these proteases for substrate cleavage after an aspartate residue turns out, with the exception of the serine protease granzyme $\mathrm{B}$, to be very rare among the protease kingdom.

Caspases are regulated at a posttranslational level, ensuring that they can be rapidly activated. All of the en- zymes are synthesized as 'procaspases', zymogens which are relatively inactive. The procaspase consists of a short or long prodomain together with one large (approx. 20 $\mathrm{kDa}$ ) and one small subunit (approx. $10 \mathrm{kDa}$ ). Procaspases-3, -6, - 7 and -14 contain a short prodomain, whereas the other procaspases carry a long prodomain that is involved in protein-protein interactions. Procaspases-1, $-2,-4,-5,-9,-11$ and -12 possess in their prodomain a caspase activation and recruitment domain (CARD), whereas procaspases- 8 and - 10 carry a tandem of 2 death effector domains (DED). These CARD and DED domains are thought to mediate the assembly of large signaling complexes which regulate the activation of these caspases [18]. The active site of the enzyme contains an invariant cysteine residue in the sequence QACXG (where $\mathrm{X}$ is $\mathrm{R}, \mathrm{Q}$ or $\mathrm{G}$ ) in the larger subunit, while the smaller subunit determines substrate specificity. Caspase enzymes are activated through proteolytic cleavage events at two sites: one site between the prodomain and the large subunit and another site between the large subunit and the small subunit. Caspase zymogens are autocleaved by scaffold-mediated transactivation or processed by upstream caspases [19]. An active enzyme is formed by a heterotetramer of two small and two large subunits [20].

Once activated, caspases cleave a variety of intracellular polypeptides and a large number of proteins have been reported to be caspase substrates [21-23]. The proteolytic cleavage can either lead to the functional inhibition or to the activation of these substrates. As mentioned above, many caspases can also propagate proteolytic activation of other family members by processing their proform through cleavage at specific aspartate residues. Caspase subtrates include major structural elements of the cytoplasm and nucleus, regulators of transcription/translation, components of the DNA repair machinery, kinases and signaling intermediaries. Caspases are almost never associated with nonspecific degradative processes, but rather with signaling events. Caspases transmit downstream signals by specific limited cleavage of key cellular components that galvanize a certain pathway.

\section{Different Playing Fields: Classification of Caspases}

During the mid-1990s, facing an increasing number of identified enzymes sharing homology with the interleukin- $1 \beta$-converting enzyme/ced-3 proteases, researchers in the field decided upon a nomenclature for the caspases [11]. It was also clear at that time that caspases are essential for the initiation and execution of 


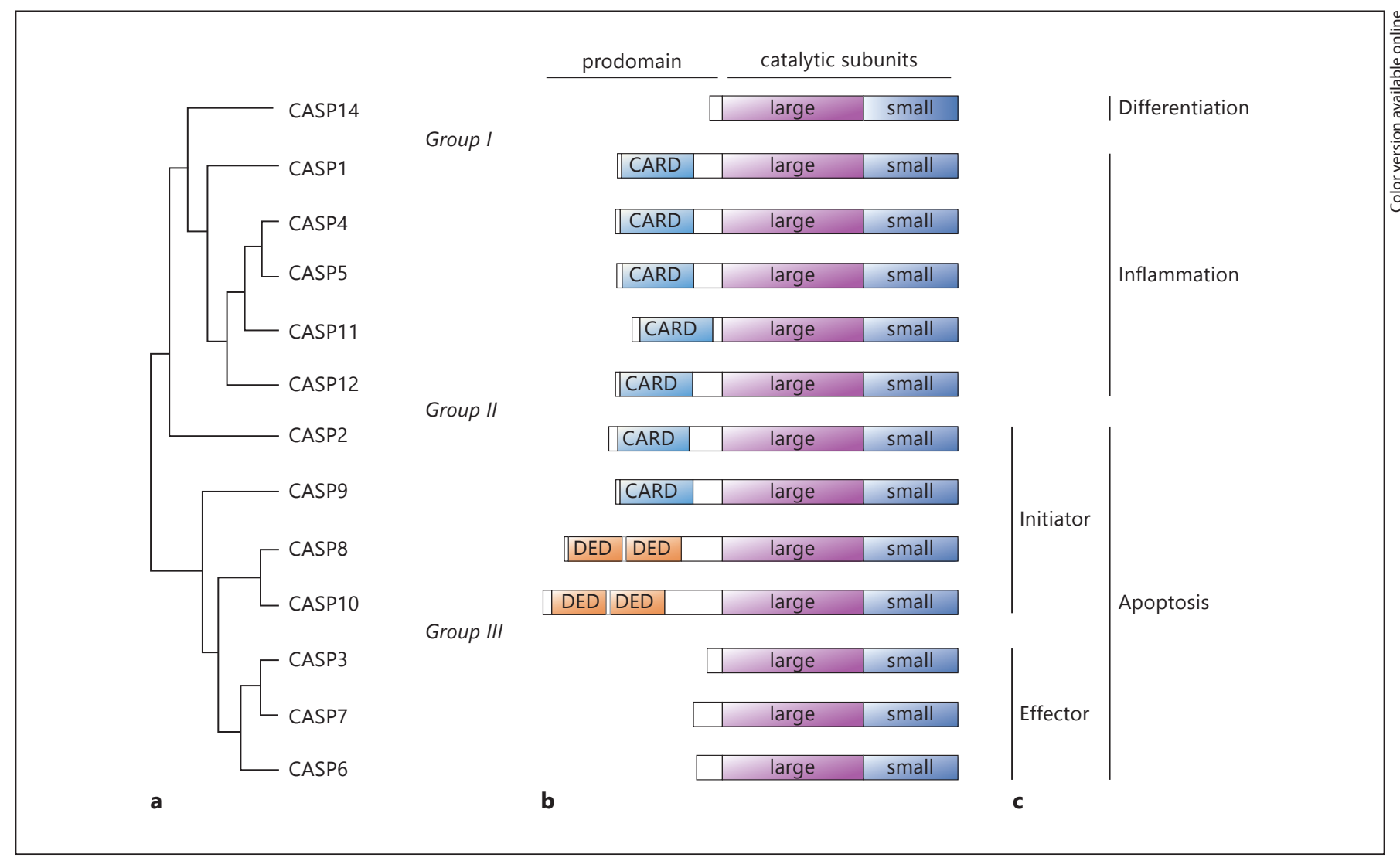

Fig. 1. Classification of caspases. a The phylogenetic relationship among caspases. Caspases segregate into two major subfamilies, the apoptotic caspases (caspases-3, -6, -7, -8, -9 and -10) and the inflammatory caspases (caspases- $1,-4,-5,-11$, and -12). Caspase- 2 and caspase-14 form their own cluster. b Caspase protein structure. Procaspases contain a short or long prodomain connected to a catalytic domain consisting of short and long subunits. Caspas- es-3, -6, -7 and -14 contain a short prodomain. Other caspases carry a long prodomain containing a CARD or a tandem of 2 DED. c Classification of caspases based on their presumptive functions. Three major groups of caspases are presented. Group I: inflammatory caspases; group II: apoptosis initiator caspases; group III: apoptosis effector caspases. Caspase-14 is required for keratinocytes differentiation. apoptosis and for the processing and maturation of the inflammatory cytokines [24]. As a result, multiple attempts have been undertaken to classify the different mammalian family members into different subgroups based on multiple criteria, i.e. phylogenetic relationships $[25,26]$, prodomain length, substrate preference $[27,28]$ and functions (fig. 1). Phylogenetic analysis based on amino acid sequence comparison suggested the existence of 3 'clusters': cluster I (caspases-1, -2, -4, -5, -12 and -14), cluster II (caspases-3, -6 and -7), and cluster III (caspases-8, -9 and -10) $[25,26]$. On the basis of different optimal cleavage substrate motifs in vitro, caspase groups have also been proposed [27, 28]; however, it is argued that this may not reflect the real caspase substrate preference in vivo and therefore should be used with caution (for a review, see Pop and Salvesen [29]). Based on the length and structural organization of the amino-terminal prodomain, caspases- $3,-6,-7$ and -14 are short prodomain proteases, whereas all others have a long prodomain folding into CARD (caspases-1, -2, -4, -5, -9, -11 and -12 ) and DED(caspases-8 and -10).

For the purposes of this review, we will focus on the classification of caspases based on their presumptive functions and location in different signaling pathways. In practice, 3 major groups of caspases are presented: group I, inflammatory caspases; group II, apoptosis initiator caspases, and group III, apoptosis effector caspases. Caspase- 14 is a unique caspase as it does not belong to either of the above-mentioned groups and is involved in terminal differentiation of epidermal keratinocytes [30]. 
During apoptosis, activated apoptotic caspases cleave selected target proteins to execute cell death and their activation is therefore often considered as a commitment to cell death [31]. The apoptotic caspases comprise 2 distinct classes: the upstream 'initiator' or 'apical' apoptotic caspases (i.e., group II caspases), which include caspases-2, $-8,-9$ and -10 , and the downstream 'effector' or 'executioner' apoptotic caspases, which include caspases-3, -6 and -7 (i.e., group III caspases). Initiator apoptotic caspases possess long prodomains containing one of two characteristic protein-protein interaction motifs: the DED (caspases-8 and -10) and the CARD (caspases-2 and -9), providing the basis for interaction with upstream adaptor molecules and activation within large multiprotein complexes. Well-defined apoptotic caspase-activating complexes include the apoptosome (activating caspase-9), the PIDDosome (activating caspase-2), and the death-inducing signaling complex (activating caspases-8 and -10) [32]. Effector caspases cleave a wide range of distinct protein substrates in different cellular compartments and are responsible for many of the changes typical of apoptosis. They are characterized by the presence of a short prodomain and are activated when cleaved by the initiator caspases. Different proapoptotic signals activate different initiators, but all the initiators activate a common set of effectors. Two major caspase-dependent pathways of apoptosis signaling have been described which trigger cell death either by activation of death receptors at the cell surface (i.e. extrinsic pathway) or via the disruption of the outer mitochondrial membrane barrier function with the simultaneous release of proapoptotic molecules from the mitochondria into the cytosol (i.e. intrinsic pathway) [33].

Caspases not only play an essential role during apoptotic cell death, but a subfamily of them, the inflammatory caspases (i.e., group I caspases), are associated with some of the inflammatory responses. Caspase-1 together with caspases- 11 and -12 in mice and caspases- 4 and -5 in humans comprise the proinflammatory caspases [34]. These caspases are characterized by the presence of a CARD in their prodomain. Of the proinflammatory caspases, caspase- 1 is the most fully characterized. Its catalytic activity is tightly regulated by signal-dependent autoactivation within multiprotein complexes called inflammasomes' that mediate caspase- 1 autocatalytic activation and the subsequent cleavage of the inactive precursors of IL- $1 \beta$ and IL- 18 into bioactive cytokines $[35,36]$. A link between caspases- $4,-5$ and -11 and the inflammatory responses has also been established (see below and Martinon and Tschopp [34]). The function of mouse caspase-12 in the inflammatory response is more controversial as a role in endoplasmic reticulum (ER) stress-induced apoptosis has been reported and then neglected [37-39]. However, the observed polymorphisms in human caspase-12 could regulate the intensity of the inflammatory response and might explain differences in the morbidity and mortality in selected populations with sepsis [13].

Thus, for many years, caspases were simply divided into 'apoptotic' and 'proinflammatory' caspases and this classification remains useful to some extent. However, increasing evidence indicates that many of these so-called apoptotic caspases also exert nonapoptotic functions (for a review, see Hyman and Yuan [40] and Venero et al. [41]). Similarly, typical 'nonapoptotic' members such as caspases- $1,-4$ and -5 are proposed to induce 'pyroptosis', a form of death associated with massive activation of inflammatory cells (for a review, see Labbe and Saleh [42]). One may wonder if the early classification of these enzymes into 'apoptotic' and 'proinflammatory' caspases might have delayed the discovery of these novel functions outside their respective group. We will review the current knowledge on the role of the different caspase family members during inflammation and highlight in particular their role in the brain.

\section{Playing as Defenders: The Inflammatory Caspases}

Neuroinflammation is a complex innate response of neural tissue against the harmful effects of diverse stimuli within the central nervous system. Infections, trauma, stroke, toxins and other stimuli are capable of producing an acute neuroinflammatory response within the central nervous system with the activation of resident immune cells (microglia, astrocytes) and the release of inflammatory mediators such as cytokines and chemokines. Neurodegenerative disorders, including Alzheimer's disease (AD), Parkinson's disease (PD), Huntington's disease, multiple sclerosis, amyotrophic lateral sclerosis, tauopathies and age-related macular degeneration, are associated with chronic neuroinflammation [43, 44]. Chronic neuroinflammation can be seen as a long-lasting and often selfperpetuating neuroinflammatory response. Chronic neuroinflammation involves the sustained activation of resident immune cells, i.e. microglia, and consequent release of proinflammatory mediators, but also an increased oxidative and nitrosative stress which are both detrimental to the neuronal cell population. 
Microglia express pattern recognition receptors (PRRs), which act as sensor for inflammatory triggers. The inflammatory response can be triggered by the recognition of several microbial signals, through conserved molecular patterns known as pathogen-associated molecular patterns [45] or intracellular molecules, normally found in the cytosol or in the nucleus, which are released from the cell after tissue damage known as danger-associated molecular patterns [46]. Pathogen-associated molecular patterns and danger-associated molecular patterns are detected by members of the Toll-like receptor (TLR) family of PRRs [47]. There are 10 functional TLRs (from TLR1 to TLR10) identified in humans and 11 (from TLR1 to TLR7, TLR9, and from TLR11 to TLR13) in mice [48, 49]. Microglia express TLR1-9; TLR1, -2, -3, -4, -5 and -6 are found on the cell surface and TLR 3 and -9 on the endosomal membranes $[50,51]$. The nucleotidebinding oligomerization domain-like receptor (NLR) family is a large family of cytosolic PRRs, specialized in the recognition of intracellular signals [52]. There are 22 NLR genes in the human genome and at least 34 NLR genes in the mouse genome. Once activated by the inflammatory stimuli, the PRRs (TLRs and NLRs) participate in the formation of multiprotein oligomers known as inflammasomes (see below), which orchestrates the activation of caspase-1 [53].

For details on the different inflammasomes, i.e. NLRP1, NLRP3, IPAF and AIM2 inflammasomes, we recommend the excellent recent review by Schroder and Tschopp [35]. Importantly, strong associations between deregulated inflammasome activity, by extension of caspase- 1 activity, and human inflammatory diseases highlight the importance of this signaling pathway in tailoring the innate immune response. Indeed, the significance of the inflammasome for the initiation of the inflammatory response during systemic diseases has already been shown and members of the inflammasome complex were recently found to be induced in acute brain injury. However, the specific pathophysiologic role of the inflammasome in neurodegenerative disorders still remains to be clarified (for a review, see Trendelenburg [54]). Interestingly, recently it was found that amyloid- $\beta$ fibrils can activate NALP3 inflammasomes via the lysosomal damage in mouse microglia [55] and they were proposed to contribute to $\mathrm{AD}$ pathology [56].

Caspase- 1 is the prototypical member of inflammatory caspases involved in cytokine maturation. This enzyme controls the processing of the inactive IL- $1 \beta$ precursor into a bioactive cytokine and a major mediator of inflammation [3,4]. Activation of caspase-1 can also promote the processing of additional cytokines, i.e. IL-
18 (IFN- $\gamma$-inducing factor) $[57,58]$, IL-37 (previously IL-1F7b) [59] and IL-33 (nuclear factor from high endothelial venule) $[60,61]$. Caspase-1 regulates both proand anti-inflammatory members of the IL- 1 family. Caspase-1-dependent cut in IL-1 $\beta$ and IL-18 procytokines results in active mature cytokines secreted into the extracellular space which galvanize the inflammatory response. The view on the biological consequence of IL-33 cleavage by caspase- 1 has changed. Whereas it was first reported that IL-33, like other IL-1 family members, requires maturation by caspase- 1 for optimal biological activity [60], it appears that caspase- 1 processing results in the inactivation of IL-33, rather than its activation [61]. Full-length IL-33 signals through the IL-1 receptor-related protein ST2 and drives the production of proinflammatory cytokines. IL-33 has also been reported to be a substrate for the apoptotic caspase-3 [61]. IL-37, an anti-inflammatory member of the IL-1 family, shares substantial homology with IL-18 and binds the IL18-binding protein; in doing so, IL-37 inhibits the activity of IL18. IL-37 also translocates to the nucleus upon maturation by caspase- 1 and acts as a transcriptional modulator reducing the production of proinflammatory cytokines [62]. The reasons why caspase- 1 regulates the activation and functions of both pro- and anti-inflammatory cytokines remain elusive.

Together with caspase- 1 , caspases- $4,-5,-11$ and -12 complete the inflammatory caspase subfamily. Mouse caspase- 11 is an orthologue of human caspases- 4 and $-5[16$, 63]. Mice deficient in caspase- 11 seem to resemble the phenotype of those lacking caspase- 1 and exhibit resistance to endotoxic shock induced by lipopolysaccharide (LPS) $[64,65]$. Recent evidence suggests that caspase-11 rather than caspase- 1 could be the critical effector of deleterious inflammatory responses. Caspase- 11 expression is required for caspase- 1 activation and secretion of IL- $1 \beta$ induced by certain stimuli, called noncanonical inflammasome activation [63]. Furthermore, TRIF downstream of TLR4 activation by Gram-negative bacteria has been reported to be essential for NLRP3 inflammasome activation and coupled to caspase-11 autoprocessing and the consequent activation of caspase-1 [66]. Caspase-11 activation is also associated with the induction of caspase-1-independent cell death $[63,66]$. Interestingly, caspase-11 potentially plays a role in the etiology of multiple sclerosis since oligodendrocytes from caspase-11-deficient mice are partially resistant to cytokine-induced cell death [67].

Human caspase- 4 and caspase- 5 show a high degree of similarity in their protein structure and are thought to arise from tandem duplication of a caspase-11-like ances- 
tral gene. Expression of these 2 caspases, as caspase-11, is induced by LPS treatment $[68,69]$. However, these 2 caspases display distinct features. Indeed, whereas the expression of caspase- 4 is normally high in all tissues, except in the brain, the opposite is observed for caspase- 5 expression levels $[70,71]$. Caspases- 4 and -5 are both found to be components of the inflammasome complexes $[71,72]$. Caspase- 5 is processed in the NLRP1 inflammasome, which also suggests that the latter might play a similar role in humans as caspase- 11 in mice. Caspase- 4 expression and most likely activity are required for activation of caspase- 1 in the NLRP 3 and Aim 2 inflammasomes. Therefore, like caspase- 1 , these 2 caspases participate in the maturation of pro-IL-1 $\beta$ and pro-IL-18 [71, 72]. Thus, caspase- 11 in mice or caspases- 4 or -5 in humans co-operatively work with caspase- 1 and might be upstream activators of caspase- 1 .

Caspase-12 is a player which has been placed in and out of the field of inflammation. The gene encoding caspase-12 is localized together with other genes for the inflammatory caspases in the same chromosomal region. In addition, caspase- 12 shares homology with caspase- 1 and was therefore classified within the subfamily of inflammatory caspases. Accumulation of unfolded proteins induces ER stress, which in turn can cause apoptosis (for a review, see Gorman et al. [73]). Murine caspase-12 has been localized on the cytoplasmic side of the ER and study of caspase-12-deficient mice suggested that this caspase is involved in ER stress-induced apoptosis [37]. As an alternative to caspase-12 in humans, caspase- 4 , which also localizes to the ER, has been linked to ER stress-induced cell death [74]. Both murine caspase- 12 and human caspase- 4 are cleaved upon ER stress $[37,74]$. In addition, the processing of caspase-12 after ER stress stimuli has been demonstrated in several disease models such as $\mathrm{AD}[37$, 75], amyotrophic lateral sclerosis [76, 77] and in prion degenerative diseases $[78,79]$. As a result of these reports, the function of caspase-12 was thought to be distinct from the inflammatory response. However, already at this point it is worth noticing that recent studies indicate that ER stress is able to elicit an inflammatory response. ER stress can generate signals which alert neighboring cells and elicit an inflammatory response to prevent more extensive tissue damage. In addition, the ability of ER stress to induce an inflammatory response is linked to the pathogenesis of neurodegenerative diseases. An even greater discrepancy results from additional studies which revealed that caspase-12-deficient cells, in both humans and mice, are as sensitive to ER stress-induced apoptosis as caspase-12-proficient cells [13, 38, 39, 80]. Even the role of caspase- 4 in ER stress-induced apoptosis has been questioned [38]. For human caspase-12, the synthesis of either a truncated CARD-only protein or a full-length protein results from a single nucleotide polymorphism on the human caspase-12 gene [13]. The truncated form of caspase-12 is prevalent within the human population, where only $20-30 \%$ of people of African descent express the full-length caspase-12 variant $[13,70]$. Full-length human caspase-12, which was initially described as an inactive form, appears to restrain the inflammatory response. A clinical study among African Americans showed that individuals bearing the full-length caspase- 12 have an increased susceptibility to sepsis [13]. Like the human fulllength variant of caspase-12, murine caspase-12 also appears to abrogate the inflammatory response. Indeed, caspase-12-deficient mice are more resistant to sepsis, and are able to clear bacterial pathogens more efficiently than wild-type mice [39]. Caspase-12 seems to exert its negative effects on inflammation through inhibition of caspase-1. Interestingly, the enzymatic function of caspase-12 is dispensable for its inhibitory effect on caspase-1. Mechanistically, caspase-12 is proposed to block caspase- 1 activation acting as a decoy caspase, similar to c-FLIP, a decoy caspase-8-like protein [39]. In summary, murine and full-length caspase-12, which belong to the caspase-1-related subfamily of inflammatory caspases, should be considered as 'anti-inflammatory caspases'.

\section{Apoptotic Caspases: Versatile Players in Regulating Brain and Peripheral Brain Responses}

Increasing evidence strongly suggests that cell differentiation and apoptosis share a common origin and hence former leading players in apoptosis are becoming prominent players in cell differentiation. As an example, nuclear disruption is viewed as an irreversible step in the apoptotic process, which precedes the final physical destruction of a cell, likewise terminal differentiation of many cell types including erythrocytes, keratinocytes, and lens fiber epithelial cells is characterized by the complete removal of the nucleus $[41,81]$. In fact, apoptotic caspases are emerging as the most versatile players in these two processes as accumulating evidence of nonapoptotic roles for these proteases during cell differentiation has notably increased in recent years. Supporting this view, inhibition of caspase- 3 activity limits nuclear condensation and extrusion in lens fiber epithelial cells, keratinocytes, and erythrocytes, and even attenuates or inhibits the differentiation of these cell types [82-85]. Of particular interest for this re- 
view, special relevance for the nonapoptotic roles of caspases has been found in the myeloid and lymphoid cell lineages. The first indication came from immunoblotting studies which demonstrate caspase-3 cleavage during early stages of $\mathrm{T}$ lymphocyte proliferation in the absence of an apparent sign of cell death [86]. Subsequent work demonstrated that caspase inhibitors could interfere with $\mathrm{T}$ lymphocyte proliferation $[87,88]$. The autoimmune lymphoproliferative syndrome is a human disorder characterized by defective lymphocyte apoptosis, lymphadenopathy, splenomegaly and autoimmunity. Chun et al. [89] described a human kindred with an inherited genetic deficiency of caspase- 8 in autoimmune lymphoproliferative syndrome. Homozygous individuals manifest defective lymphocyte apoptosis and homeostasis but, unlike individuals affected with autoimmune lymphoproliferative syndrome, also have defects in their activation of T lymphocytes, B lymphocytes and natural killer cells, which leads to immunodeficiency. With regard to the myeloid cell lineage, Sordet et al. [90] demonstrated the requirement of apoptotic caspases for the differentiation of monocytes into macrophages but not into dendritic cells. They observed limited but significant activation of caspases- 3 and -9 in these cells without the presence of apoptotic features [90]. Additional studies established that caspase- 8 acts as the upstream enzyme responsible for the activation of caspases- 3 and -9 , which in turn control the differentiation of peripheral blood monocytes into macrophages. The formation of a molecular platform including caspase-8, the adaptor protein Fas-associated death domain (FADD), the serine/threonine kinase receptorinteracting protein 1 (RIP1) and the long isoform of the FLICE-inhibitory protein FLIP were also described [91] in the process dependent on oscillatory activation of phosphatidylinositol-3-kinase and AKT [92]. Under these conditions, active caspase- 8 cleaves RIP1, which in turn downregulates NF- $\kappa \mathrm{B}$ during the differentiation process [91]. These studies confirmed previous findings obtained with a mouse model of conditional caspase- 8 gene knockout in the myeloid cell lineage demonstrating restricted monocyte differentiation into macrophages [93].

Microglia are believed to derive from monocytes that invade the developing central nervous system and persist over the adult life as resident macrophages [94, 95]. A recent study using fate-mapping analysis confirmed that these glial cells derive indeed from primitive myeloid progenitors that arise before embryonic day 8 [96] and that the postnatal hematopoietic progenitors do not contribute to microglia homeostasis in the adult brain. Similarities between the activated resident microglia and the pe- ripheral macrophages are evident. Actually, any attempt to find specific molecules at mRNA or protein levels that would definitively distinguish activated microglia from other types of macrophages in their expression of surface markers has failed so far. We recently described a novel and unexpected role for caspases- $8,-3$ and -7 in the activation of microglia and associated neurotoxicity. This finding may be relevant in the onset of chronic neurodegenerative diseases, mainly $\mathrm{PD}$ and $\mathrm{AD}$ [97]. We will briefly summarize the main findings of the referred article. We found that activation of microglial BV2 cells with different proinflammogens including LPS (a TLR4 agonist), lipoteichoic acid (TLR2 agonist), PamC3sk4 (TLR1/2 agonist) and IFN- $\gamma$ led to modest but yet significant caspase- $3 / 7$ activities in the absence of cell death (as evaluated by morphological features, mitochondrial dysfunction and PARP cleavage). Chemical inhibition of either caspases- 3 or -7 in BV2 cells led to robust reduction of microglia activation in terms of iNOS induction, IKK- $\beta$ expression, ROS formation and the production of certain cytokines in response to various proinflammogens. Identical results were obtained upon genetic knockdown of caspases- 3 or -7 , which were also associated with a reduction in the nuclear translocation of NF- $\mathrm{BB}$. Altogether, these results highlight the importance for these executioner caspases in the control of microglia activation. A prerequisite for a nonapoptotic role of a killer caspase is to limit its activation and/or restrict its activity to specific cell compartments. Our data indicate that both phenomena contributed to the nonapoptotic role. Indeed, moderate caspase- 3 activities were observed after stimulation with the above-mentioned proinflammogens as compared to those seen after treatment with a classical death stimulus (i.e. staurosporine treatment). In addition, cleaved caspase- 3 was found to localize primarily close to the plasma membrane and was not present in the nucleus [97]. Caspase- 8 was found to act as an upstream caspase in this signaling pathway, since chemical inhibition or gene knockdown using siRNAs of caspase- 8 prevented caspase-3/7 activition and the subsequent appearance of typical molecular features of microglia activation. The central role for caspases- $8,-3$ and -7 in the regulation of microglia activation was moreover established in vivo. Single intranigral injection of LPS induces an acute inflammatory response with a strong macrophage/microglial reaction and results in the selective and progressive death of dopaminergic but not GABAergic neurons in the substantia nigra $[98,99]$. Under these conditions, we observed a strong induction of caspase- 8 and activation of caspase-3, which was mostly confined to reactive microg- 
lia as evaluated by OX-6 immunoreactivity. Intranigral administration of DEVD-fluoromethyl ketone (fmk), a caspase-3 inhibitor, or rottlerin, a PKC $\delta$ inhibitor, mitigated LPS-induced expression of cytokines and proinflammatory molecules, therefore supporting the view that killer caspases play a significant role in the activation of microglia. Since unregulated response or overactivation of microglia can have disastrous neurotoxic consequences, especially to the dopaminergic system $[41,100]$, we also tested the ability of intranigral administration of IETD-fmk, a caspase- 8 inhibitor, to prevent microglia activation and preserve the integrity of the dopaminergic system in the MPTP-lesion mouse model of PD. We found that caspase- 8 inhibition in vivo significantly reduced the density of activated microglia and promoted a modest but yet significant protection of the nigrostriatal dopaminergic system. Consequently, we concluded that caspases- $8,-3$ and -7 control microglia activation and neurotoxicity [97]. To confirm that these findings may have physiopathological consequences in chronic neurodegenerative diseases, we analyzed postmortem frontal cortex and ventral mesencephalon from patients who have been diagnosed with $\mathrm{AD}$ and $\mathrm{PD}$, respectively. Evidence of extensive inflammatory response in these two diseases is well documented [101]. We monitored the expression of cleaved caspase-3 and cleaved caspase-8, which correspond to the active forms of these enzymes, and the microglia marker CD68 in the referred brain areas and found significant cytoplasmic expression for these two active caspases in the PD ventral mesencephalon and in the $\mathrm{AD}$ frontal cortex, as compared with controls. The broad use of caspase inhibitors has been traditionally aimed at preventing apoptotic neuronal death under different lesion paradigms. Little attention has, however, been paid to the glial response in response to in vivo administration of caspase inhibitors. Recently, Chauvier et al. [102] have developed a pentapeptide-based group II caspase inhibitor, TRP601/ORPHA133563, which reaches the brain, and inhibits caspase activation in vivo. This study demonstrated that pharmacological inhibition of caspases- 2 and -3 with TRP601 reduces cortical and white matter damage in three different models of neonatal brain damage after excitotoxicity, arterial stroke and hypoxiaischemia. Worth a notice, in all of these experimental paradigms, TRP601 also reduces microgliosis, the inflammatory response to brain ischemia. In accord with these results, Al-Jamal et al. [103] have developed a unique nonviral gene vector based on functionalized carbon nanotube to deliver caspase- 3 siRNA in a rodent model of focal ischemic cortical damage and found reduced neu- rodegeneration and increased functional preservation. The authors demonstrated that the functional carbon nanotubes can effectively transport siRNA into primary neurons [103]. It would be interesting to investigate whether there is an uptake of this biomaterial by microglial cells and a potential subsequent effect of the inflammatory response. In fact, severe nanotube structure deformation in vivo led to their internalization by microglia [104]. It is to conclude that selective caspase inhibition within the microglial cell population may offer a new tool to modulate the brain immune response exacerbated in numerous neurodegenerative diseases.

\section{Apoptotic Caspases during Development}

Gene ablation of caspase- 8 results in embryonic lethality around embryonic day E10.5, a finding supporting a prosurvival role for this protein during development [105]. Near-identical consequences are found after knocking out FADD $[106,107]$ and FLIP [108], thus raising a common prosurvival role for these proteins. Several studies have shown that Fas or TNFR activation leads to necrotic cell death upon caspase inhibition in various cell lines including L929 mouse fibroblasts, mouse embryonic fibroblasts, and Jurkat T cells [109-111]. Accumulating evidence supports an essential role of the serine/threonine kinases RIPK1 and RIPK3 in caspase-independent necrosis $[109,110]$ termed 'programmed necrosis' or 'necroptosis' (for reviews, see Lee et al. [112], Feoktistova et al. [113] and Moquin and Chan [114]). Interestingly, two independent studies recently demonstrated that the development of caspase-8-deficient mice is completely rescued by ablation of RIPK3 $[115,116]$. The ability of RIPK3 ablation to rescue the lethal phenotype of caspase- 8 deletion in mice suggests that one essential role for caspase- 8 during development is to suppress RIPK3-dependent necrosis. In addition, the adult animals displayed a sign of a progressive lymphoaccumulative disease, a view compatible with a nonapoptotic role of caspase- 8 in immune cell proliferation $[115,116]$. Caspase- 8 acting in a proteolytically active complex with $\operatorname{FLIP}_{\mathrm{L}}$ prevents RIPK3-dependent necrosis [115]. FLIP is a transcriptional target of NF- $\kappa B$ [117], and caspase- 8 and FADD have also been reported to be required for NF- $\kappa B$ activation and proliferation in microglia, T lymphocytes and $\mathrm{B}$ cells, in response to the innate pattern recognition receptors TLR3 and TLR4 [97, 118-120]. It is, therefore, not surprising that some authors have sought to explain the defects observed in embryos and immune cells deficient in 


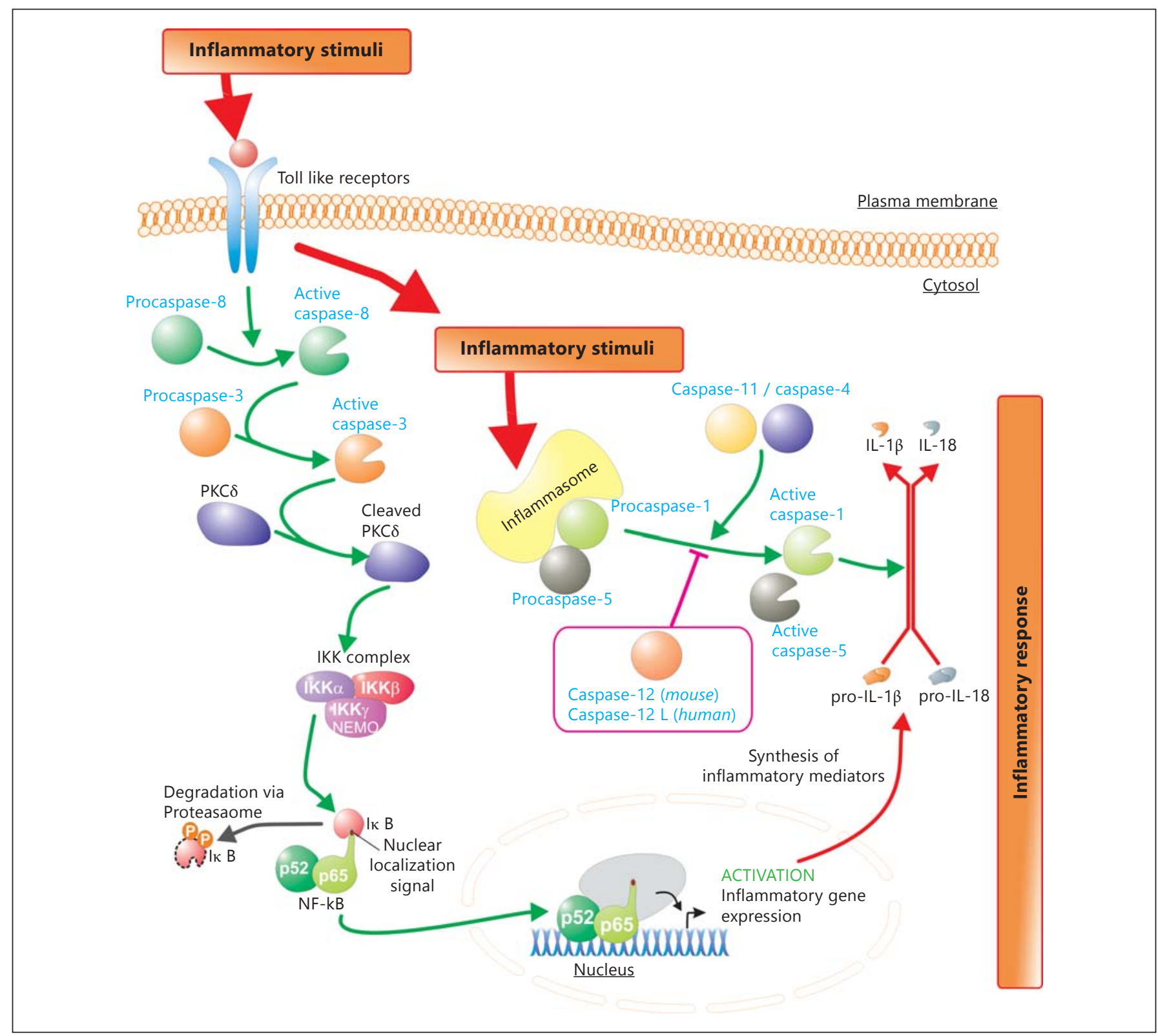

Fig. 2. Caspases playing in the field of neuroinflammation: old and new players. Inflammatory stimuli signal both via the TLR system and the NLR/inflammasome pathway. Activation of TLRs leads to the orderly activation of caspase- 8 and caspase- 3 . Caspase- 3 activates the NF- $\kappa \mathrm{B}$ pathways through processing and activation of PKC $\delta$. Nuclear accumulation of NF- $\mathrm{kB}$ leads to the transcriptional activation of inflammatory gene expression including the cytokines

caspase-8, FADD or FLIP by the implication of these proteins in the induction of NF- $\kappa$ B signaling [120]. Consequently, new nonapoptotic roles of caspase- 8 in regulating innate and adaptive responses are strongly emerging during development and adulthood. The old-established precursor pro-IL-1 $\beta$ and pro-IL-18. Inflammasome formation leads to caspase- 1 and caspase- 5 activation. Activation of caspase- 1 results in the processing and release of the proinflammatory cytokines IL-1 $\beta$ and IL-18. Caspase- 11 in mice or caspase- 4 in humans co-operatively work with caspase- 1 and might be upstream activators of caspase-1. Murine or human full-length caspase-12 is shown to downregulate the inflammatory response by directly inhibiting caspase- 1 . 


\section{Perspectives}

In this review, we have highlighted the original role for apoptotic caspases- $8,-3$ and -7 in the activation of microglia and associated neurotoxicity besides the established role of the so-called inflammatory caspases (fig. 2). We also shed light into the other nonapoptotic roles of caspase- 8 in the differentiation and activation of myeloid and lymphoid cell lineages including lymphocytes and monocytes/macrophages. Given the expanding evidence supporting a key role for the peripheral inflammation in the regulation of brain inflammation [121] and the deleterious roles of infiltrating peripheral leukocytes in acute and chronic conditions, the role of caspase- 8 should be considered in the context of the whole inflammatory brain response given the mutual nonexclusive interactions among these cells. Leukocyte infiltration is considered as a rather expected outcome during acute lesion models (e.g. stroke). Studies support this view in animal models of chronic neurodegenerative diseases. For instance, radiation bone marrow chimera has been used to demonstrate extensive myeloid GFP-positive cells in the proximity of amyloid plaques in transgenic animal models of $\mathrm{AD}[122,123]$. Consequently, any intervention aimed at targeting caspase- 8 should consider the overall effect of this initiator caspase in the different inflammatory cellular phenotypes.

Whatever interventions are aimed at modulating/influencing the microglial function, one should consider the dual role of microglia (beneficial vs. detrimental). Microglia and macrophages can be classified into at least two subsets with distinct molecular phenotypes and effector functions depending on the activation pathway. The 'classically activated' proinflammatory M1 macrophages, activated by LPS and by the proinflammatory cytokine IFN- $\gamma$, produce high amounts of oxidative metabolites, proteases and proinflammatory cytokines. They play a central role in the host defense against pathogens and tumor cells, but they can also damage healthy cells such as neurons and glial cells. In contrast, M2 macrophages or 'alternatively activated', induced by IL- 4 and IL-13, exhibit anti-inflammatory properties and promote tissue remodeling/repair and angiogenesis [124]. We have demonstrated the involvement of cleaved caspase- 8 in classically activated proinflammatory M1 macrophages. The role of caspase- 8 in alternatively activated M2 macrophages remains to be established. Lalanncette-Hebert et al. [125], using transgenic mice exhibiting the selective ablation of proliferating microglia, demonstrated a protective role for microglia after middle cerebral artery occlusion. The selective ablation of proliferating microglial cells after transient middle cerebral artery occlusion was associated with a marked deregulation of postischemic brain inflammatory response, an increase in the size of the ischemic lesion and a significant increase in the number of apoptotic cells, predominantly neurons, and a significant decrease in the levels of the neurotrophic factor IGF1, expressed by Mac-2-positive/proliferating microglia in the areas around the ischemic lesion. It remains to be analyzed whether caspase- 8 plays a significant role in Mac2-positive/proliferating microglia in acute and chronic injury conditions. Further studies involving selective in vivo gene targeting of caspase- 8 specifically in microglia are necessary to ascertain the precise role of this caspase in orchestrating the heterogenous microglia cell responses.

Given the extremely wide range of functions of caspases, it is plausible to consider the usefulness of targeting caspases as a therapeutic strategy. Killing caspases are emerging as a key player in the regulation of the immune responses and interventions aimed at minimizing caspase-dependent brain inflammatory responses are certainly hopeful. We recently reported that the intranigral administration of fmk-derivative tetrapeptide caspase inhibitors - DEVD-fmk targeting caspases-3/7 or IETD-fmk targeting caspase- 8 - hindered in vivo microglia activation [97]. The required administration mode for these caspase inhibitors certainly limits their use in a clinical setting. Furthermore, fmk metabolizes in the liver to form fluoroacetate, an extremely toxic poison [126]. Newer third-generation caspase inhibitors are, however, promising tools as their toxicity has been greatly reduced. However, we should be careful when inhibiting caspase- 8 since its activity prevents cells from inducing programmed necrosis, a condition that could be relevant under inflammatory conditions.

In conclusion, this review is opposed to the idea that caspases would be players put together in different groups based on their talent in different areas of the game to be played within the cell; the cell represents the entire playing field, and depending on the action undertaken, the caspases that form a team will coordinate actions to fulfill the goal to be achieved in the cell.

\section{Acknowledgements}

This work has been supported by grants from the Spanish Ministerio de Ciencia y Tecnología (SAF2009-13778) and Proyecto de Excelencia from the Junta de Andalucía (CTS-6494), the Swedish Research Council, the Parkinson Foundation of Sweden, the Swedish Childhood Cancer Foundation the Swedish Cancer Society and the Michael J. Fox Foundation. M.A.B. is supported by a fellowship from the Swedish Research Council. 


\section{References}

1 Black RA, Kronheim SR, Merriam JE, March CJ, Hopp TP: A pre-aspartate-specific protease from human leukocytes that cleaves prointerleukin-1 beta. J Biol Chem 1989;264: 5323-5326.

-2 Kostura MJ, Tocci MJ, Limjuco G, Chin J, Cameron P, Hillman AG, Chartrain NA, Schmidt JA: Identification of a monocyte specific pre-interleukin 1 beta convertase activity. Proc Natl Acad Sci USA 1989;86:52275231.

$\checkmark 3$ Cerretti DP, Kozlosky CJ, Mosley B, Nelson N, Van Ness K, Greenstreet TA, March CJ, Kronheim SR, Druck T, Cannizzaro LA, et al: Molecular cloning of the interleukin-1 beta converting enzyme. Science 1992;256:97100.

4 Thornberry NA, Bull HG, Calaycay JR, Chapman KT, Howard AD, Kostura MJ, Miller DK, Molineaux SM, Weidner JR, Aunins J, et al: A novel heterodimeric cysteine protease is required for interleukin-1 beta processing in monocytes. Nature 1992;356:768-774.

$\checkmark 5$ Yuan J, Shaham S, Ledoux S, Ellis HM, Horvitz HR: The C. elegans cell death gene ced-3 encodes a protein similar to mammalian interleukin-1 beta-converting enzyme. Cell 1993;75:641-652.

6 Miura M, Zhu H, Rotello R, Hartwieg EA, Yuan J: Induction of apoptosis in fibroblasts by IL-1 beta-converting enzyme, a mammalian homolog of the C. elegans cell death gene ced-3. Cell 1993;75:653-660.

7 Nicholson DW, Ali A, Thornberry NA, Vaillancourt JP, Ding CK, Gallant M, Gareau Y, Griffin PR, Labelle M, Lazebnik YA, et al: Identification and inhibition of the ICE/ CED-3 protease necessary for mammalian apoptosis. Nature 1995;376:37-43.

$>8$ Schlegel J, Peters I, Orrenius S, Miller DK, Thornberry NA, Yamin TT, Nicholson DW: CPP32/apopain is a key interleukin 1 beta converting enzyme-like protease involved in fas-mediated apoptosis. J Biol Chem 1996; 271:1841-1844.

9 Thornberry NA, Lazebnik Y: Caspases: Enemies within. Science 1998;281:1312-1316.

10 Samali A, Zhivotovsky B, Jones D, Nagata S, Orrenius S: Apoptosis: cell death defined by caspase activation. Cell Death Differ 1999;6: 495-496.

$>11$ Alnemri ES, Livingston DJ, Nicholson DW, Salvesen G, Thornberry NA, Wong WW, Yuan J: Human ICE/CED-3 protease nomenclature. Cell 1996;87:171.

-12 Martinon F, Tschopp J: Inflammatory caspases: linking an intracellular innate immune system to autoinflammatory diseases. Cell 2004;117:561-574.
13 Saleh M, Vaillancourt JP, Graham RK, Huyck M, Srinivasula SM, Alnemri ES, Steinberg $\mathrm{MH}$, Nolan V, Baldwin CT, Hotchkiss RS, Buchman TG, Zehnbauer BA, Hayden MR, Farrer LA, Roy S, Nicholson DW: Differential modulation of endotoxin responsiveness by human caspase-12 polymorphisms. Nature 2004;429:75-79.

14 Fernandes-Alnemri T, Armstrong RC, Krebs J, Srinivasula SM, Wang L, Bullrich F, Fritz LC, Trapani JA, Tomaselli KJ, Litwack G, Alnemri ES: In vitro activation of CPP32 and Mch3 by Mch4, a novel human apoptotic cysteine protease containing two FADD-like domains. Proc Natl Acad Sci USA 1996;93: 7464-7469.

15 Reed JC, Doctor K, Rojas A, Zapata JM, Stehlik C, Fiorentino L, Damiano J, Roth W, Matsuzawa S, Newman R, Takayama S, Marusawa H, Xu F, Salvesen G, Godzik A: Comparative analysis of apoptosis and inflammation genes of mice and humans. Genome Res 2003;13: 1376-1388.

16 Koenig U, Eckhart L, Tschachler E: Evidence that caspase-13 is not a human but a bovine gene. Biochem Biophys Res Commun 2001; 285:1150-1154.

17 Fuentes-Prior P, Salvesen GS: The protein structures that shape caspase activity, specificity, activation and inhibition. Biochem 2004;384:201-232.

18 Park HH, Lo YC, Lin SC, Wang L, Yang JK, $\mathrm{Wu} \mathrm{H}$ : The death domain superfamily in intracellular signaling of apoptosis and inflammation. Annu Rev Immunol 2007;25:561586.

19 Ramage P, Cheneval D, Chvei M, Graff P, Hemmig R, Heng R, Kocher HP, Mackenzie A, Memmert K, Revesz L, et al: Expression, refolding, and autocatalytic proteolytic processing of the interleukin-1 beta-converting enzyme precursor. J Biol Chem 1995;270: 9378-9383.

20 Stennicke HR, Salvesen GS: Catalytic properties of the caspases. Cell Death Differ 1999;6: 1054-1059.

21 Luthi AU, Martin SJ: The CASBAH: a searchable database of caspase substrates. Cell Death Differ 2007; 14:641-650.

22 Crawford ED, Wells JA: Caspase substrates and cellular remodeling. Annu Rev Biochem 2011;80:1055-1087.

23 Timmer JC, Salvesen GS: Caspase substrates. Cell Death Differ 2007;14:66-72.

24 Wong WW: ICE family proteases in inflammation and apoptosis. Agents Actions Suppl 1998;49:5-13.

25 Miller DK, Myerson J, Becker JW: The interleukin-1 beta converting enzyme family of cysteine proteases. J Cell Biochem 1997;64: $2-10$.

-26 Lamkanfi M, Declercq W, Kalai M, Saelens X, Vandenabeele P: Alice in caspase land. A phylogenetic analysis of caspases from worm to man. Cell Death Differ 2002;9:358-361.
27 Thornberry NA, Rano TA, Peterson EP, Rasper DM, Timkey T, Garcia-Calvo M, Houtzager VM, Nordstrom PA, Roy S, Vaillancourt JP, Chapman KT, Nicholson DW: A combinatorial approach defines specificities of members of the caspase family and granzyme B. Functional relationships established for key mediators of apoptosis. J Biol Chem 1997;272:17907-17911.

28 Lavrik IN, Golks A, Krammer PH: Caspases: pharmacological manipulation of cell death. J Clin Invest 2005;115:2665-2672.

29 Pop C, Salvesen GS: Human caspases: activation, specificity, and regulation. J Biol Chem 2009;284:21777-21781.

-30 Lippens S, Kockx M, Knaapen M, Mortier L, Polakowska R, Verheyen A, Garmyn M, Zwijsen A, Formstecher P, Huylebroeck D, Vandenabeele P, Declercq W: Epidermal differentiation does not involve the pro-apoptotic executioner caspases, but is associated with caspase-14 induction and processing. Cell Death Differ 2000;7:1218-1224.

31 Riedl SJ, Shi Y: Molecular mechanisms of caspase regulation during apoptosis. Nat Rev Mol Cell Biol 2004;5:897-907.

32 Mace PD, Riedl SJ: Molecular cell death platforms and assemblies. Curr Opin Cell Biol 2010;22:828-836.

33 Zimmermann KC, Bonzon C, Green DR: The machinery of programmed cell death. Pharmacol Ther 2001;92:57-70.

34 Martinon F, Tschopp J: Inflammatory caspases and inflammasomes: master switches of inflammation. Cell Death Differ 2007;14:10-22.

35 Schroder K, Tschopp J: The inflammasomes. Cell 2010;140:821-832.

36 van de Veerdonk FL, Netea MG, Dinarello CA, Joosten LA: Inflammasome activation and IL-1beta and IL-18 processing during infection. Trends Immunol 2011;32:110-116.

37 Nakagawa T, Zhu H, Morishima N, Li E, Xu J, Yankner BA, Yuan J: Caspase-12 mediates endoplasmic-reticulum-specific apoptosis and cytotoxicity by amyloid-beta. Nature 2000;403:98-103.

38 Obeng EA, Boise LH: Caspase-12 and caspase- 4 are not required for caspase-dependent endoplasmic reticulum stress-induced apoptosis. J Biol Chem 2005;280:2957829587.

-39 Saleh M, Mathison JC, Wolinski MK, Bensinger SJ, Fitzgerald P, Droin N, Ulevitch RJ, Green DR, Nicholson DW: Enhanced bacterial clearance and sepsis resistance in caspase12-deficient mice. Nature 2006;440:10641068 .

40 Hyman BT, Yuan J: Apoptotic and non-apoptotic roles of caspases in neuronal physiology and pathophysiology. Nat Rev Neurosci 2012; 13:395-406. 
-41 Venero JL, Burguillos MA, Brundin P, Joseph $B$ : The executioners sing a new song: killer caspases activate microglia. Cell Death Differ 2011;18:1679-1691.

42 Labbe K, Saleh M: Cell death in the host response to infection. Cell Death Differ 2008; 15 : 1339-1349.

-43 Hagberg H, Gressens P, Mallard C: Inflammation during fetal and neonatal life: implications for neurologic and neuropsychiatric disease in children and adults. Ann Neurol 2012; 71:444-457.

-44 Frank-Cannon TC, Alto LT, McAlpine FE, Tansey MG: Does neuroinflammation fan the flame in neurodegenerative diseases? Mol Neurodegener 2009;4:47.

-45 Akira S, Uematsu S, Takeuchi O: Pathogen recognition and innate immunity. Cell 2006; 124:783-801.

46 Beg AA: Endogenous ligands of toll-like receptors: implications for regulating inflammatory and immune responses. Trends Immunol 2002;23:509-512.

-47 Akira S, Takeda K: Toll-like receptor signalling. Nat Rev Immunol 2004;4:499-511.

-48 Kawai T, Akira S: TLR signaling. Cell Death Differ 2006;13:816-825.

49 Takeda K, Kaisho T, Akira S: Toll-like receptors. Annu Rev Immunol 2003;21:335-376.

50 Bsibsi M, Ravid R, Gveric D, van Noort JM: Broad expression of toll-like receptors in the human central nervous system. J Neuropathol Exp Neurol 2002;61:1013-1021.

51 Lee SJ, Lee S: Toll-like receptors and inflammation in the cns. Curr Drug Targets Inflamm Allergy 2002;1:181-191.

-52 Strober W, Murray PJ, Kitani A, Watanabe T: Signalling pathways and molecular interactions of NOD1 and NOD2. Nat Rev Immunol 2006;6:9-20.

53 Yazdi AS, Drexler SK, Tschopp J: The role of the inflammasome in nonmyeloid cells. J Clin Immunol 2010;30:623-627.

54 Trendelenburg G: Acute neurodegeneration and the inflammasome: central processor for danger signals and the inflammatory response? J Cereb Blood Flow Metab 2008;28: 867-881.

55 Halle A, Hornung V, Petzold GC, Stewart CR, Monks BG, Reinheckel T, Fitzgerald KA, Latz E, Moore KJ, Golenbock DT: The NALP3 inflammasome is involved in the innate immune response to amyloid-beta. Nature immunology 2008;9:857-865.

-56 Salminen A, Ojala J, Suuronen T, Kaarniranta $\mathrm{K}$, Kauppinen A: Amyloid-beta oligomers set fire to inflammasomes and induce Alzheimer's pathology. J Cell Mol Med 2008;12:22552262.

57 Fantuzzi G, Puren AJ, Harding MW, Livingston DJ, Dinarello CA: Interleukin-18 regulation of interferon gamma production and cell proliferation as shown in interleukin-1betaconverting enzyme (caspase-1)-deficient mice. Blood 1998;91:2118-2125.
Ghayur T, Banerjee S, Hugunin M, Butler D, Herzog L, Carter A, Quintal L, Sekut L, Talanian R, Paskind M, Wong W, Kamen R, Tracey D, Allen $\mathrm{H}$ : Caspase-1 processes IFN-gamma-inducing factor and regulates LPS-induced IFN-gamma production. Nature 1997; 386:619-623.

59 Kumar S, Hanning CR, Brigham-Burke MR, Rieman DJ, Lehr R, Khandekar S, Kirkpatrick RB, Scott GF, Lee JC, Lynch FJ, Gao W, Gambotto A, Lotze MT: Interleukin-1F7B (IL$1 \mathrm{H} 4 / \mathrm{IL}-1 \mathrm{~F} 7)$ is processed by caspase- 1 and mature IL-1F7B binds to the IL-18 receptor but does not induce IFN-gamma production. Cytokine 2002;18:61-71.

60 Schmitz J, Owyang A, Oldham E, Song Y, Murphy E, McClanahan TK, Zurawski G, Moshrefi M, Qin J, Li X, Gorman DM, Bazan JF, Kastelein RA: IL-33, an interleukin-1-like cytokine that signals via the IL-1 receptor-related protein ST2 and induces T helper type 2-associated cytokines. Immunity 2005;23: 479-490.

61 Cayrol C, Girard JP: The IL-1-like cytokine IL-33 is inactivated after maturation by caspase-1. Proc Natl Acad Sci USA 2009;106: 9021-9026.

62 Sharma S, Kulk N, Nold MF, Graf R, Kim SH, Reinhardt D, Dinarello CA, Bufler P: The IL-1 family member $7 \mathrm{~b}$ translocates to the nucleus and down-regulates proinflammatory cytokines. J Immunol 2008;180:5477-5482.

63 Kayagaki N, Warming S, Lamkanfi M, Vande Walle L, Louie S, Dong J, Newton K, Qu Y, Liu J, Heldens S, Zhang J, Lee WP, Roose-Girma M, Dixit VM: Non-canonical inflammasome activation targets caspase-11. Nature 2011; 479:117-121.

64 Li P, Allen H, Banerjee S, Franklin S, Herzog L, Johnston C, McDowell J, Paskind M, Rodman L, Salfeld J, et al: Mice deficient in IL-1 beta-converting enzyme are defective in production of mature IL-1 beta and resistant to endotoxic shock. Cell 1995;80:401-411.

65 Wang S, Miura M, Jung YK, Zhu H, Li E, Yuan J: Murine caspase-11, an ice-interacting protease, is essential for the activation of ice. Cell 1998;92:501-509.

66 Rathinam VA, Vanaja SK, Waggoner L, Sokolovska A, Becker C, Stuart LM, Leong JM, Fitzgerald KA: TRIF licenses caspase-11-dependent NLRP 3 inflammasome activation by gram-negative bacteria. Cell 2012;150:606619.

67 Hisahara S, Yuan J, Momoi T, Okano H, Miura M: Caspase-11 mediates oligodendrocyte cell death and pathogenesis of autoimmunemediated demyelination. Journal Exp Med 2001;193:111-122.

68 Lin XY, Choi MS, Porter AG: Expression analysis of the human caspase- 1 subfamily reveals specific regulation of the CASP 5 gene by lipopolysaccharide and interferon-gamma. J Biol Chem 2000;275:39920-39926.
9 Bian ZM, Elner SG, Elner VM: Dual involvement of caspase-4 in inflammatory and ER stress-induced apoptotic responses in human retinal pigment epithelial cells. Invest Ophthalmol Vis Sci 2009;50:6006-6014.

70 Nadiri A, Wolinski MK, Saleh M: The inflammatory caspases: key players in the host response to pathogenic invasion and sepsis. J Immunol 2006;177:4239-4245.

71 Sollberger G, Strittmatter GE, Kistowska M, French LE, Beer HD: Caspase- 4 is required for activation of inflammasomes. J Immunol 2012;188:1992-2000

72 Martinon F, Burns K, Tschopp J: The inflammasome: a molecular platform triggering activation of inflammatory caspases and processing of proIL-beta. Mol Cell 2002;10:417426.

73 Gorman AM, Healy SJ, Jager R, Samali A: Stress management at the ER: regulators of ER stress-induced apoptosis. Pharmacol Ther 2012;134:306-316.

74 Hitomi J, Katayama T, Eguchi Y, Kudo T, Taniguchi M, Koyama Y, Manabe T, Yamagishi S, Bando Y, Imaizumi K, Tsujimoto Y, Tohyama M: Involvement of caspase-4 in endoplasmic reticulum stress-induced apoptosis and abeta-induced cell death. J Cell Biol 2004; 165:347-356.

75 Quiroz-Baez R, Ferrera P, Rosendo-Gutierrez $\mathrm{R}$, Moran J, Bermudez-Rattoni F, Arias C: Caspase- 12 activation is involved in amyloidbeta protein-induced synaptic toxicity. J Alzheimers Dis 2011;26:467-476.

76 Wootz H, Hansson I, Korhonen L, Napankangas U, Lindholm D: Caspase-12 cleavage and increased oxidative stress during motoneuron degeneration in transgenic mouse model of als. Biochem Biophys Res Commun 2004;322:281-286.

77 Vijayalakshmi K, Alladi PA, Ghosh S, Prasanna VK, Sagar BC, Nalini A, Sathyaprabha TN, Raju TR: Evidence of endoplasmic reticular stress in the spinal motor neurons exposed to CSF from sporadic amyotrophic lateral sclerosis patients. Neurobiol Dis 2011;41:695705.

78 Hetz C, Russelakis-Carneiro M, Maundrell K, Castilla J, Soto C: Caspase-12 and endoplasmic reticulum stress mediate neurotoxicity of pathological prion protein. EMBO J 2003;22: 5435-5445.

79 Hetz C, Russelakis-Carneiro M, Walchli S, Carboni S, Vial-Knecht E, Maundrell K, Castilla J, Soto C: The disulfide isomerase GRP58 is a protective factor against prion neurotoxicity. J Neurosci 2005;25:2793-2802.

80 Di Sano F, Ferraro E, Tufi R, Achsel T, Piacentini M, Cecconi F: Endoplasmic reticulum stress induces apoptosis by an apoptosomedependent but caspase 12-independent mechanism. J Biol Chem 2006;281:2693-2700.

-81 Fernando P, Megeney LA: Is caspase-dependent apoptosis only cell differentiation taken to the extreme? FASEB J 2007;21:8-17. 
82 Zermati Y, Garrido C, Amsellem S, Fishelson S, Bouscary D, Valensi F, Varet B, Solary E, Hermine $\mathrm{O}$ : Caspase activation is required for terminal erythroid differentiation. Journal Exp Med 2001;193:247-254.

83 Weil M, Raff MC, Braga VM: Caspase activation in the terminal differentiation of human epidermal keratinocytes. Curr Biol 1999;9: 361-364.

84 Okuyama R, Nguyen BC, Talora C, Ogawa E, Tommasi di Vignano A, Lioumi M, Chiorino G, Tagami H, Woo M, Dotto GP: High commitment of embryonic keratinocytes to terminal differentiation through a notch1-caspase 3 regulatory mechanism. Dev Cell 2004; 6:551-562.

85 Zandy AJ, Lakhani S, Zheng T, Flavell RA, Bassnett S: Role of the executioner caspases during lens development. J Biol Chem 2005; 280:30263-30272.

-86 Miossec C, Dutilleul V, Fassy F, Diu-Hercend A: Evidence for CPP32 activation in the absence of apoptosis during T lymphocyte stimulation. J Biol Chem 1997;272:13459-13462.

-87 Kennedy NJ, Kataoka T, Tschopp J, Budd RC: Caspase activation is required for $\mathrm{T}$ cell proliferation. J Exp Med 1999;190:1891-1896.

-88 Boissonnas A, Bonduelle O, Lucas B, Debre P, Autran B, Combadiere B: Differential requirement of caspases during naive $T$ cell proliferation. Eur J Immunol 2002;32:3007-3015.

-89 Chun HJ, Zheng L, Ahmad M, Wang J, Speirs CK, Siegel RM, Dale JK, Puck J, Davis J, Hall CG, Skoda-Smith S, Atkinson TP, Straus SE, Lenardo MJ: Pleiotropic defects in lymphocyte activation caused by caspase- 8 mutations lead to human immunodeficiency. Nature 2002;419:395-399.

90 Sordet O, Rebe C, Plenchette S, Zermati Y, Hermine O, Vainchenker W, Garrido C, Solary E, Dubrez-Daloz L: Specific involvement of caspases in the differentiation of monocytes into macrophages. Blood 2002; 100:4446-4453.

91 Rebe C, Cathelin S, Launay S, Filomenko R, Prevotat L, L'Ollivier C, Gyan E, Micheau O, Grant S, Dubart-Kupperschmitt A, Fontenay M, Solary E: Caspase- 8 prevents sustained activation of NF-kappaB in monocytes undergoing macrophagic differentiation. Blood 2007;109:1442-1450.

\$2 Jacquel A, Benikhlef N, Paggetti J, Lalaoui N, Guery L, Dufour EK, Ciudad M, Racoeur C, Micheau O, Delva L, Droin N, Solary E: Colony-stimulating factor-1-induced oscillations in phosphatidylinositol-3 kinase/AKT are required for caspase activation in monocytes undergoing differentiation into macrophages. Blood 2009;114:3633-3641.

93 Kang TB, Ben-Moshe T, Varfolomeev EE, Pewzner-Jung Y, Yogev N, Jurewicz A, Waisman A, Brenner O, Haffner R, Gustafsson E, Ramakrishnan P, Lapidot T, Wallach D: Caspase-8 serves both apoptotic and nonapoptotic roles. J Immunol 2004;173:29762984.
94 Alliot F, Godin I, Pessac B: Microglia derive from progenitors, originating from the yolk sac, and which proliferate in the brain. Brain Res Dev Brain Res 1999;117:145-152.

95 Gomes-Leal W: Microglial physiopathology: how to explain the dual role of microglia after acute neural disorders? Brain Behav 2012;2:345-356.

$\$ 96$ Ginhoux F, Greter M, Leboeuf M, Nandi S, See P, Gokhan S, Mehler MF, Conway SJ, Ng LG, Stanley ER, Samokhvalov IM, Merad M: Fate mapping analysis reveals that adult microglia derive from primitive macrophages. Science 2010;330:841-845.

-97 Burguillos MA, Deierborg T, Kavanagh E, Persson A, Hajji N, Garcia-Quintanilla A, Cano J, Brundin P, Englund E, Venero JL, Joseph B: Caspase signalling controls microglia activation and neurotoxicity. Nature 2011;472:319-324.

-98 Castano A, Herrera AJ, Cano J, Machado A: Lipopolysaccharide intranigral injection induces inflammatory reaction and damage in nigrostriatal dopaminergic system. J Neurochem 1998;70:1584-1592.

-99 Herrera AJ, Castano A, Venero JL, Cano J, Machado A: The single intranigral injection of LPS as a new model for studying the selective effects of inflammatory reactions on dopaminergic system. Neurobiol Dis 2000;7: 429-447.

100 Brown GC, Neher JJ: Inflammatory neurodegeneration and mechanisms of microglial killing of neurons. Mol Neurobiol 2010;41: 242-247.

101 Glass CK, Saijo K, Winner B, Marchetto MC, Gage FH: Mechanisms underlying inflammation in neurodegeneration. Cell 2010; 140:918-934.

102 Chauvier D, Renolleau S, Holifanjaniaina S, Ankri S, Bezault M, Schwendimann L, Rousset C, Casimir R, Hoebeke J, Smirnova M, Debret G, Trichet AP, Carlsson Y, Wang X, Bernard E, Hebert M, Rauzier JM, Matecki S, Lacampagne A, Rustin P, Mariani J, Hagberg H, Gressens P, Charriaut-Marlangue C, Jacotot $\mathrm{E}$ : Targeting neonatal ischemic brain injury with a pentapeptide-based irreversible caspase inhibitor. Cell Death Dis 2011; 2:e203.

103 Al-Jamal KT, Gherardini L, Bardi G, Nunes A, Guo C, Bussy C, Herrero MA, Bianco A, Prato M, Kostarelos K, Pizzorusso T: Functional motor recovery from brain ischemic insult by carbon nanotube-mediated siRNA silencing. Proc Natl Acad Sci USA 2011;108: 10952-10957.

104 Nunes A, Bussy C, Gherardini L, Meneghetti M, Herrero MA, Bianco A, Prato M, Pizzorusso T, Al-Jamal KT, Kostarelos K: In vivo degradation of functionalized carbon nanotubes after stereotactic administration in the brain cortex. Nanomedicine (Lond) 2012;7:1485-1494.
105 Varfolomeev EE, Schuchmann M, Luria V, Chiannilkulchai N, Beckmann JS, Mett IL, Rebrikov D, Brodianski VM, Kemper OC, Kollet O, Lapidot T, Soffer D, Sobe T, Avraham KB, Goncharov T, Holtmann H, Lonai P, Wallach D: Targeted disruption of the mouse caspase 8 gene ablates cell death induction by the TNF receptors, Fas/Apo1, and DR3 and is lethal prenatally. Immunity 1998;9:267-276.

106 Zhang J, Cado D, Chen A, Kabra NH, Winoto A: Fas-mediated apoptosis and activation-induced T-cell proliferation are defective in mice lacking FADD/Mort1. Nature 1998;392:296-300.

107 Yeh WC, Pompa JL, McCurrach ME, Shu HB, Elia AJ, Shahinian A, Ng M, Wakeham A, Khoo W, Mitchell K, El-Deiry WS, Lowe SW, Goeddel DV, Mak TW: FADD: essential for embryo development and signaling from some, but not all, inducers of apoptosis. Science 1998;279:1954-1958.

108 Yeh WC, Itie A, Elia AJ, Ng M, Shu HB, Wakeham A, Mirtsos C, Suzuki N, Bonnard M, Goeddel DV, Mak TW: Requirement for Casper (c-FLIP) in regulation of death receptor-induced apoptosis and embryonic development. Immunity 2000;12: 633-642.

109 Holler N, Zaru R, Micheau O, Thome M, Attinger A, Valitutti S, Bodmer JL, Schneider P, Seed B, Tschopp J: Fas triggers an alternative, caspase-8-independent cell death pathway using the kinase rip as effector molecule. Nat Immunol 2000;1:489-495.

110 Lin Y, Choksi S, Shen HM, Yang QF, Hur GM, Kim YS, Tran JH, Nedospasov SA, Liu ZG: Tumor necrosis factor-induced nonapoptotic cell death requires receptor-interacting protein-mediated cellular reactive oxygen species accumulation. J Biol Chem 2004;279:10822-10828.

-111 Vercammen D, Brouckaert G, Denecker G, Van de Craen M, Declercq W, Fiers W, Vandenabeele P: Dual signaling of the Fas receptor: initiation of both apoptotic and necrotic cell death pathways. J Exp Med 1998;188: 919-930.

112 Lee EW, Seo J, Jeong M, Lee S, Song J: The roles of FADD in extrinsic apoptosis and necroptosis. BMB Rep 2012;45:496-508.

113 Feoktistova M, Geserick P, PanayotovaDimitrova D, Leverkus M: Pick your poison: the ripoptosome, a cell death platform regulating apoptosis and necroptosis. Cell Cycle 2012;11:460-467.

114 Moquin D, Chan FK: The molecular regulation of programmed necrotic cell injury. Trends Biochem Sci 2010;35:434-441.

115 Oberst A, Dillon CP, Weinlich R, McCormick LL, Fitzgerald P, Pop C, Hakem R, Salvesen GS, Green DR: Catalytic activity of the caspase-8-FLIP(L) complex inhibits RIPK3dependent necrosis. Nature 2011;471:363367. 
116 Kaiser WJ, Upton JW, Long AB, LivingstonRosanoff D, Daley-Bauer LP, Hakem R, Caspary T, Mocarski ES: RIP3 mediates the embryonic lethality of caspase-8-deficient mice. Nature 2011;471:368-372.

117 Ozturk S, Schleich K, Lavrik IN: Cellular FLICE-like inhibitory proteins (c-FLIPs): fine-tuners of life and death decisions. Exp Cell Res 2012;318:1324-1331.

118 Su H, Bidere N, Zheng L, Cubre A, Sakai K, Dale J, Salmena L, Hakem R, Straus S, Lenardo M: Requirement for caspase-8 in NFkappaB activation by antigen receptor. Science 2005;307:1465-1468.
119 Imtiyaz HZ, Rosenberg S, Zhang Y, Rahman ZS, Hou YJ, Manser T, Zhang J: The Fas-associated death domain protein is required in apoptosis and TLR-induced proliferative responses in B cells. J Immunol 2006;176: 6852-6861.

120 Oberst A, Green DR: It cuts both ways: reconciling the dual roles of caspase 8 in cell death and survival. Nat Rev Mol Cell Biol 2011;12:757-763.

121 Perry VH: Contribution of systemic inflammation to chronic neurodegeneration. Acta Neuropathol 2010;120:277-286.

122 Simard AR, Soulet D, Gowing G, Julien JP, Rivest S: Bone marrow-derived microglia play a critical role in restricting senile plaque formation in Alzheimer's disease. Neuron 2006;49:489-502.
123 Stalder AK, Ermini F, Bondolfi L, Krenger W, Burbach GJ, Deller T, Coomaraswamy J, Staufenbiel M, Landmann R, Jucker M: Invasion of hematopoietic cells into the brain of amyloid precursor protein transgenic mice. J Neurosci 2005;25:11125-11132.

124 Czeh M, Gressens P, Kaindl AM: The yin and yang of microglia. Dev Neurosci 2011 33:199-209.

125 Lalancette-Hebert M, Gowing G, Simard A, Weng YC, Kriz J: Selective ablation of proliferating microglial cells exacerbates ischemic injury in the brain. J Neurosci 2007;27: 2596-2605.

126 Gribble GW: Fluoroacetate toxicity. J Chem Educ 1973;50:460-462. 